\title{
ALGUNOS PRINCIPIOS DE POLÍTICA ECONÓMICA A CONSIDERARSE EN LOS PLANES DE GOBIERNO DEL PERÍODO 2011-2016
}

\author{
SOME PRINCIPLES OF ECONOMIC CONSIDERATIONS IN THE PLANS OF \\ GOVERNMENT OF THE PERIOD 2011-2016
}

\author{
Pablo Rivas Santos* \\ Docente de la Facultad de Ciencias Económicas - UNMSM
}

[Recepción: Marzo de 2011/ Conformidad: Abril de 2011]

\section{RESUMEN}

La función del Gobierno es proteger y defender la vida y propiedad de las personas que se encuentren bajo su jurisdicción (contra las agresiones internas o externas); arreglar las disputas que puedan surgir; y dejar al pueblo (en lo demás) libre para alcanzar sus propias metas.

La función del gobierno es ser guardián de las condiciones que permitirán a familias y empresas alcanzar sus propias metas. Si el gobierno hace eso, la gente podría proveerse a sí misma de la mejor manera.

Cuando el gobierno protege los derechos de la gente para que hagan lo que quieran (en tanto no infrinjan la igual libertad de los demás para hacer lo mismo) harán lo que le nace: trabajar, cooperar y comerciar unos con otros. Entonces, tendrán el incentivo de ahorrar, acumular capital, innovar, experimentar, aprovechar las oportunidades y producir.

La mejor política económica es limitar la acción del gobierno a crear las condiciones para que la gente pueda alcanzar sus propias metas y vivir en paz con sus vecinos. La función del gobierno es permitir a la gente disfrutar la libertad y oportunidad de cooperar y comerciar unos con otros. Así, el gobierno

\begin{abstract}
The Government's role is to protect and defend life and property of people who are under its jurisdiction (against internal or external aggression) to settle disputes that may arise, and let the people (the other) free to achieve their goals.

The role of government is to be guardian of the conditions that enable families and businesses achieve their goals. If the government does that, people could provide for themselves the best.

When the government protects the rights of people to do what they want (as do not violate the equal freedom of others to do the same) will do what is born: to work, cooperate and trade with each other. Then, have the incentive to save, accumulate capital, innovate, experiment, seize opportunities and produce.

The best policy is to limit government action to create conditions for people to achieve their own goals and live in peace with its neighbors. The role of government is to enable people to enjoy freedom and opportunity to cooperate and trade with each other. Thus, the government creates the economic environment that allows each em-
\end{abstract}

\footnotetext{
* Egresado de Maestría de la Facultad de Ciencias Económicas - UNMSM, Docente Investigador de la Facultad de Ciencias Económicas - UNMSM. E-mail: privass@unmsm.edu.pe
} 
crea el entorno económico que permite que cada empresario tenga el derecho de servir mejor a su cliente.

Palabras claves. Libertad económica. Inflación. Intervencionismo. Inversión extranjera.

\section{INTRODUCCIÓN}

Los líderes de los grandes negocios mantienen su liderazgo mientras sirvan mejor a su clientela. Estos líderes dependen del sector productivo en el que operan y de los clientes a los que sirven. Deben mantenerse en buenos términos con sus consumidores; pierde su liderazgo tan pronto no pueda dar a sus clientes un mejor servicio, y proveerlo a un menor costo, que los otros con quienes compite.

Hay personas que tratan de organizar a otras personas para producir. Estas personas producen cosas más baratas para cubrir las necesidades de todos. La producción en masa para satisfacer las necesidades de las masas es el principio fundamental de la industria. Las industrias producen cosas que son compradas por la población.

Son los trabajadores de las grandes empresas los principales consumidores de los productos hechos en esas empresas.

En las tiendas se oye decir 'el cliente tiene la razón' Y este cliente es la misma persona que produce en las fábricas esos productos que son vendidas en las tiendas. El poder de las grandes empresas es limitado, ya que dependen de la voluntad de los que compran sus productos. Esas grandes empresas pierden poder e influencia; cuando pierden clientela.

El poder de los medios de comunicación depende de la habilidad para servir mejor a la gente. La libertad para competir en comunicaciones significa inventar algo, hacer algo, que sea un desafío a las comunicaciones y ployer has the right to better serve its customers.

Key words: Economic freedom. Inflation. Interventionism. foreign investment.

los ponga en una buena situación competitiva. El desarrollo de la economía de mercado consiste en que cada uno tenga el derecho de servir a su cliente mejor.

Perú en 1950, tenía más 7 millones de habitantes con un nivel de vida menor. Hoy con casi 30 millones de personas disfrutan un nivel de vida mayor. El nivel de vida de hoy sería más alto; si una gran cantidad de energía de los peruanos no se hubiese desperdiciado en guerras internas y externas y políticas inflacionistas.

Las fábricas exportadoras proveen a las necesidades de sus trabajadores directa o indirectamente, exportando productos no tradicionales e importando insumos y maquinarias.

Una autoridad visita una fábrica de camisas en Gamarra y el propietario de la fábrica, le dice: 'Vea, aquí hay camisas de algodón para EEUU'. Esa exportación significa que ese propietario produce para sus propios trabajadores ya que la exportación trae dólares para mejorar los salarios de los trabajadores. Si hay escasez de máquinas y dólares en Lima, esas máquinas y dólares debían ser importados de EEUU, UE y Japón. Esa exportación era la manera de pagar las importaciones de máquinas y dólares que hacían posible el mantenimiento de los trabajadores.

En la actualidad hay relativamente poca diferencia entre la vida básica de las clases altas y bajas; ambas clases tienen comida, ropa y casa. En Lima hoy la diferencia entre un hombre rico y un hombre pobre significa la diferencia entre un Audi y un Volkswagen. 
El Volkswagen puede haber sido comprado de segunda mano pero, básicamente, le da el mismo servicio a su propietario: él, también, puede manejar de un lugar a otro.

Es correcto: distinguir entre trabajador y consumidor; y establecer una diferencia entre ellos. Pero cada consumidor debe ganarse el dinero que gasta, y la mayoría de los consumidores son las mismas personas que trabajan en las empresas que producen las cosas que ellos consumen. Así, el nivel de salarios es fijado por una clase de gente que es la misma clase de gente que gana los salarios.

Si los consumidores no le pagan al empresario lo suficiente para permitirle pagar a sus trabajadores, se tornará imposible para el empresario permanecer en el negocio ${ }^{1}$.

Las mejoras sociales son el resultado de la acumulación de capital; están basadas en el hecho de que la gente, como norma, no consume todo lo que produce, que ahorra e invierte - una parte.

Los ahorros significan beneficios para todos aquellos que desean producir o ganar un salario. Cuando una persona ahorra una cierta suma de dinero - digamos mil soles - en un banco; el dinero va a las manos de un empresario, permitiéndole embarcarse en un proyecto, en el cual no podría haberse embarcado ayer; pues el capital requerido no estaba disponible. El primer uso que debe hacer con este capital adicional es salir a contratar trabajadores y comprar materias primas, lo cual provoca: una adicional demanda de trabajadores y materias primas; y una tendencia hacia más altos salarios y más altos precios de las materias primas. Mucho antes que el ahorrista o el empresario obtenga ganancia de todo esto, es el trabajador (antes desempleado) y el productor de las materias primas, quienes se reparten los beneficios del incremento del ahorro.

El momento en que el empresario obtendrá algo de su proyecto, depende: de las futuras condiciones del mercado; y de su habilidad en anticipar correctamente esas futuras condiciones del mercado. Pero los trabajadores y productores de materias primas obtienen sus beneficios inmediatamente. Una nueva rama de negocio, o una nueva fábrica en una rama de negocio ya existente, tienen que atraer trabajadores de otros empleos, de otras partes del país. Y la única manera de atraerlos es ofrecer a los trabajadores un mayor salario por su trabajo.

Por supuesto, un gran porcentaje de estos nuevos trabajadores no habían ganado nada antes de ello y estaban dispuestos a aceptar cualquier cosa que les ofrecieran. Pero después de un corto período de tiempo (cuando más capital se acumulaba y más nuevas empresas se desarrollaban) los niveles de salario crecieron, y el resultado fue el crecimiento en la población.

Un incremento de los salarios reales provocará en un incremento de la población, y en una mejora del nivel de vida.

Pero, esta mejora del nivel de vida depende del suministro de capital. En Perú se han instaurado métodos modernos para combatir enfermedades contagiosas y el efecto ha sido el crecimiento de la población; pero, como este crecimiento no ha ido acompañado de un incremento en el monto del capital invertido, el resultado ha sido un incremento de la pobreza. Un país se vuelve más próspero en proporción al incremento del capital invertido por habitante.

1 Hay gente que considera injusto que un hombre, que debe mantener una familia de 6 hijos, reciba el mismo salario que un hombre que solamente debe mantenerse a sí mismo. ¿Está Ud. dispuesto -como consumidor- a pagar más por un polo, si se le dice que el hombre que hizo este polo tiene 6 hijos? La persona honesta contestará por la negativa y dirá: 'Sí, pero, si cuesta menos, mejor compraría el polo producido por un hombre sin hijos' 


\section{INFLACIÓN}

Cuando un gobierno aumenta indebidamente la cantidad de dinero; el poder de compra del dinero cae, la cantidad de bienes que puede comprarse con ese dinero también cae, y suben los precios. Esto se denomina inflación. La causa de la inflación es el aumento indebido de la cantidad de dinero.

Bajo las actuales condiciones tecnológicas, nada es más fácil que producir pedazos de papel sobre los que se imprimen cantidades dinerarias. En el país donde todos los billetes son del mismo tamaño, no le cuesta más al gobierno imprimir un billete de 200 soles que imprimir un billete de 10 soles. Se trata de un procedimiento de impresión que requiere la misma cantidad de tinta y papel.

No hay secreto para solucionar los problemas financieros de un gobierno; si necesita dinero, tiene que obtenerlo gravando con impuestos a los ciudadanos (o tomando préstamos de la gente que tenga dinero) Pero los gobiernos, piensan que hay otro método para obtener dinero que necesitan $\mathbf{i}$ imprimirlo !

Si el gobierno desea construir un hospital; la forma de obtener dinero para construirlo es gravar con impuestos a los ciudadanos. No ocurrirá ningún aumento de precios; ya que cuando el gobierno cobra impuesto para construir el hospital, los ciudadanos (que han pagado sus impuestos) están obligados a reducir sus gastos: su consumo, su inversión o su ahorro. El gobierno, apareciendo en el mercado como comprador, reemplaza al ciudadano: el ciudadano compra menos y el gobierno compra más. El gobierno no siempre compra los mismos bienes que compra el ciudadano, pero no suben los precios debido a que el gobierno construye el hospital ${ }^{2}$.
El gobierno podría usar el dinero de los impuestos para contratar nuevos empleados o aumentar los sueldos de aquellos que están nombrados. Entonces esa gente, cuyos salarios han aumentado, pueden comprar más. Cuando el gobierno grava con impuestos a los ciudadanos y usa ese dinero para aumentar los sueldos de los empleados públicos, los contribuyentes tienen menos para gastar, y los empleados públicos tienen más para gastar. Los precios no subirán.

Pero si el gobierno (para este fin) usa el dinero recién impreso; habrá gente que ahora tiene más dinero; y gente que tendrá la misma cantidad de los que tenía antes. Así, aquellos que recibieron el dinero recién impreso competirán con aquella gente que ya antes era compradora. $\mathrm{Y}$ dado que no hay más productos de los que antes existía; pero hay más dinero en el mercado -y dado que ahora hay gente que puede comprar más que ayer- habrá una demanda adicional por la misma cantidad de bienes. Como consecuencia, los precios subirán. Esta tendencia de los precios de subir se desarrolla paso a paso. Los precios no suben con la misma amplitud ni en el mismo momento. Siempre hay precios que suben más rápidamente que otros precios.

Considere el ejemplo del empleado público que recibió ese dinero adicional. La gente no compra hoy los mismos bienes ni en las mismas cantidades; como lo hizo ayer. El dinero adicional que el gobierno imprimió e introdujo en el mercado es utilizado para comprar ciertos bienes, cuyos precios subirán, mientras que otros bienes se mantendrán con los mismos precios vigentes (antes que ese dinero adicional fuera puesto en el mercado). Por ello, cuando comienza la inflación, diferentes grupos de la población son

2 Se elige este ejemplo porque la gente dice: 'Hay una diferencia si el gobierno usa el dinero para buenos o malos fines'. Se supone que el gobierno siempre usa el dinero (que ha impreso) para buenos fines. Pero lo que provoca la inflación es la forma como se obtiene el dinero. 
afectados por esta inflación en forma diferente. Aquellos grupos que obtieuen ese dinero adicional son los primeros en ganar un beneficio temporal.

Cuando el gobierno aumenta la cantidad de dinero para reactivar la demanda agregada, mediante compras estatales, los primeros en obtener el dinero adicional son los empresarios nacionales y los trabajadores de esas empresas. Estos grupos están ahora en una posición muy favorable. Tienen mayores ganancias y mayores sueldos; su negocio se mueve; porque ellos fueron los primeros en recibir el dinero adicional. Y teniendo ahora más dinero; compran a otro grupo que está fabricando y vendiendo los productos que desean esos empresarios nacionales. Este otro grupo forma un segundo grupo. $Y$ este segundo grupo considera a la inflación como muy buena para los negocios. Porque es bueno vender más. Por ejemplo, el propietario de un restaurante en la vecindad de una fábrica nacional dice: los trabajadores de las fábricas de productos nacionales tienen más dinero, hay mucho más trabajadores ahora que antes, todos vienen a mi restaurante.

Esa gente a quienes llega primero el dinero adicional; ahora tienen un mayor ingreso y todavía pueden comprar muchos productos a precios que corresponden a la anterior situación del mercado, (situación que existía al comienzo de la inflación). Por tanto, están en una posición favorable. $Y$ así la inflación continúa paso a paso, de un grupo de la población a otro grupo.

Pero hay otros grupos de la población a quienes ese dinero adicional les llega muy tarde. Esta gente está en una posición desfavorable. Antes que ese dinero adicional les llegue, están obligados a pagar mayores precios que los que antes pagaban por todos los productos que desean comprar en tanto que su ingreso continúa siendo el mismo.
Entre 1974-1990; la inflación favoreció a las empresas estatales y a sus trabajadores, y perjudicó a otros grupos de la población. Los que sufrieron las mayores desventajas por la inflación fueron los maestros, policías, campesinos y trabajadores independientes.

Por un largo tiempo, tuvieron que: comprar menos que lo que compraban antes, reducir su consumo de alimentos, restringir su compra de ropa; ya que los precios subían y sus salarios no subían.

Por tanto, hay diferentes grupos en la población afectados en forma desigual por la inflación. Para unos grupos, la inflación no es tan mala; más aún, piden que continúe porque son los primeros en obtener provecho de la inflación.

Esta desigualdad en los efectos de la inflación; afecta las políticas monetarias que conduce a la inflación.

Bajo estos cambios causados por la inflación, hay: grupos favorecidos por la inflación porque se dan cuenta de lo que sucede más rápidamente que el resto de la gente (sus ganancias especiales se deben al hecho de que necesariamente habrá desigualdad en el proceso inflacionario) y grupos de especuladores que especulan.

El gobierno puede pensar que la inflación -como método de obtener dinero- es mejor que gravar con impuestos que es impopular y dificultoso. Los congresistas habían discutido, las diferentes formas de nuevos impuestos que se volvían necesarios; ya que el gobierno había decidido aumentar el gasto estatal. Habiendo discutido los diferentes métodos de obtener dinero mediante impuestos, finalmente decidían que quizás era mejor obtenerlo mediante la inflación.

Las técnicas para hacer inflación son tan complicados que el hombre de la calle no se da cuenta que la inflación ha empezado. 
Las técnicas para hacer inflación se complican porque existe el dinero bancario. El gobierno de un plumazo crea dinero por decreto (dinero fiat), aumentando así la cantidad de dinero y crédito. El gobierno emite una orden, y el dinero aparece por decreto.

$\mathrm{Al}$ comienzo, al gobierno no le preocupa que algunas personas pierdan y que los precios suban. Esta política tiene una debilidad: no puede durar. La inflación debe terminar tarde o temprano. En el largo plazo la inflación destruye la moneda; se llega a una situación como la de 1988-90.

Para mucha gente el largo plazo rápidamente se convierte en corto plazo; y mientras más tiempo continúe la inflación, más rápido se cumplirá ese corto plazo.

El BCR puede continuar con la inflación probablemente todo el tiempo que la gente continúe convencida de que el $\mathrm{BCR}$, tarde o temprano (pero no demasiado tarde) dejará de imprimir dinero y de ese modo detendrá la reducción del valor del dinero.

La gente no cree más en el gobierno, cuando se da cuenta que el gobierno seguirá y seguirá sin intención de detenerse, entonces comenzarán a entender que mañana los precios serán más altos que hoy. Entonces comenzarán a comprar a cualquier precio, haciendo que los precios suban a tales alturas que el sistema monetario se cae.

Entre 1971-1976, la gente creía que la inflación era un asunto temporal, que pronto terminaría. Lo creyeron por 5 años, hasta 1976. Entonces, empezaron a dudar. Como la inflación continuaba, la gente pensó que era más prudente comprar cualquier cosa en vez de guardar el dinero en sus bolsillos. Además pensó que no se debía dar préstamos en dinero, sino que era una buena idea ser un deudor. $Y$ así la inflación continuaba alimentándose a sí misma.
Y la inflación continuó hasta 1988. La gente creía que el dinero inflacionario era dinero real, pero entonces descubrieron que las condiciones habían cambiado. Hacia el final de la inflación en 1988, las fábricas pagaban a sus trabajadores, cada semana, por adelantado, el salario del día. Y el trabajador, que llegaba a la fábrica con su esposa, le entregaba inmediatamente su salario -todos los millones de intis que le pagaban. Y la señora inmediatamente iba al mercado a comprar cualquier cosa. Ella se daba cuenta lo que la gente ya sabía en ese momento; que durante la noche, de un día para el otro, el inti perdía $50 \%$ de su poder de compra. El dinero se derretía en los bolsillos de la gente. Esta última fase de la inflación no duró mucho tiempo; después de un corto tiempo, toda la pesadilla se había terminado: el inti no tenía valor y debió crearse el nuevo sol.

Antes de 1990 la gente consideraba ridículo hablar de una vuelta al Patrón moneda sana. Pero tal Patrón tiene una ventaja: la cantidad de dinero bajo tal Patrón es independiente de las políticas de los gobiernos. Es una forma de protección contra los gobiernos derrochadores. Si, bajo tal Patrón, se le pide a un gobierno gastar dinero en algo nuevo, el Ministro de Economía decía: ' $Y$ donde consigo el dinero? Dígame, como haré para conseguir el dinero para ese nuevo gasto'

Bajo un sistema monetario inflacionario, para los políticos nada es más fácil hacer; que ordenar a la imprenta del gobierno proveerle cuanto dinero necesitan para sus proyectos. Bajo tal sistema, un gobierno responsable tiene una oportunidad; sus líderes pueden decirle al pueblo 'No podemos hacerlo a menos que subamos los impuestos'. Pero bajo condiciones inflacionarias, la gente considera al gobierno como una institución con medios ilimitados a su disposición: el go- 
bierno, puede hacer cualquier cosa. Si el país desea carreteras, se espera que el gobierno lo construya. Pero ¿dónde obtendrá el dinero el gobierno?

Fue un gobierno responsable quien vetó una decisión del Congreso de dar dinero para ayudar a las empresas estatales que habían sufrido pérdidas. Tal gobierno justificó su veto diciendo: 'es deber de los ciudadanos mantener al gobierno, pero no es deber del gobierno mantener a los ciudadanos'.

El concepto del sistema monetario inflacionario (un aumento de la cantidad de dinero reduce el poder de compra del nuevo sol) es lo que no le gusta a la gente cuyos asuntos privados son desfavorablemente afectados. La gente que no se beneficia de la inflación, es la gente que se queja.

Si la inflación es perjudicial, y la gente se da cuenta de eso, ¿por qué se ha convertido en una forma de vida en todos los países? Hay un constante debate sobre la inflación; y la necesidad de detenerla. Pero solamente hablan, no actúan.

Después de la hiperinflación, Perú retornó a la paridad un nuevo sol = un dólar. Revaluó el nuevo sol. Esto aumentó el poder de compra de los salarios. En el mercado laboral, el salario nominal debería haber caído para compensar esa revaluación ( $y$ el salario real no debería haber caído. Pero los sindicatos no estaban dispuestos a aceptar esa reducción del salario nominal en razón de tal aumento del poder de compra. En consecuencia, los salarios reales aumentaron considerablemente por esa medida monetaria. Esta fue un problema para el país, ya que: debe importar maquinarias e insumos para producir, y exportar materias primas y productos no tradicionales para pagar esas importaciones. Con el aumento del valor del nuevo sol, los precios de las exportaciones peruanas subieron en los mercados extranjeros y las expor- taciones cayeron. Perú había establecido sus precios fuera del mercado mundial.

Conocemos el poder de los sindicatos. Pueden recurrir a la violencia. Y por tanto, una orden del sindicato es no menos importante que un decreto gubernamental. El decreto gubernamental es una orden para cuyo cumplimiento se encuentra disponible el aparato estatal y la policía. Un decreto gubernamental debe obedecerse, de lo contrario se tendrá problemas con la policía. Tenemos un segundo poder que tiene la posibilidad de usar la fuerza: los sindicatos. Los sindicatos establecen salarios y luego hacen una huelga para ponerlos en práctica de la misma manera en que el gobierno decreta el salario mínimo. Es política de los sindicatos presionar por el incremento de los salarios a niveles por encima de los niveles que tendrían en el mercado. Como resultado, una parte considerable de la potencial fuerza laboral puede ser empleada solamente por empresarios que estén dispuestas a sufrir pérdidas. Y, dado que los negocios no pueden mantenerse sufriendo pérdidas, cierran sus puertas y los empleados se convierten en desempleados. Establecer salarios por encima del nivel que tendrían en el mercado resulta siempre en el desempleo de una parte considerable de la potencial fuerza laboral.

El resultado de los altos niveles salariales (obligado por el gobierno y sindicatos) fue un desempleo, prolongado año tras año. Millones de trabajadores estaban sin empleo, la producción caía. En esta situación el gobierno tomó una decisión que consideró una medida indispensable, de emergencia: depreció la moneda.

El resultado fue que el poder de compra del salario nominal (sobre los que los sindicatos habían insistido) se redujo. El salario real se redujo. Ahora al trabajador no le era posible comprar todo lo que le había sido 
posible comprar antes, aún cuando el salario nominal permanecía en el mismo alto nivel. Se pensó que pronto el salario real retornaría a los niveles del mercado y el desempleo desaparecería.

Era un método oculto para frustrar el poder del gobierno y los sindicatos. Pero, no podría llamársele un éxito real.

Pocos años después, los sindicatos se dieron cuenta que la depreciación de la moneda había reducido sus salarios reales. Los sindicatos tenían el poder para oponerse a esto. Insertaron una cláusula en los contratos laborales: los salarios nominales deben incrementarse automáticamente con el aumento de precios. Esto se denomina indexación. Los sindicatos se hicieron conscientes de los índices de precios del consumidor. Así, ese método oculto de reducir el desempleo ya no funciona.

Algunos economistas elevaron este método a la categoría de sistema de política. Y lo justificaron: 'El desempleo es malo. Si desea que el desempleo desaparezca, debe incrementarse la cantidad de dinero'

Entendían que los niveles de salarios pueden ser: demasiado alto para el mercado, demasiado alto para hacer rentable a un empresario incrementar su fuerza laboral; por tanto demasiado alto desde el punto de vista de la población laboral, dado que con niveles de salarios impuesto por los sindicatos por encima del nivel de mercado, solamente una parte de los que están ansiosos por ganar un sueldo, obtendrán trabajo.

Decían que: 'el desempleo masivo, prolongado año tras año, es una mala situación'
Pero en vez de sugerir que los salarios se ajusten a las condiciones del mercado, decían: 'Si uno deprecia la moneda y los trabajadores no se dan cuenta, no pondrán resistencia contra una caída de los salarios reales, en tanto los salarios nominales permanezcan iguales' Ellos decían que si un trabajador gana hoy el mismo monto que ganaba antes que la moneda fuera depreciada, no se daría cuenta que ahora está ganando menos.

Los salarios se deben ajustar a las condiciones del mercado. El pleno empleo tiene que ver con un mercado laboral no manipulado por sindicatos ni gobierno. En este mercado, el nivel de salario para cada tipo de trabajo tiende a llegar a un punto en el que todo aquel que desea trabajo puede obtenerlo y cada empleador puede contratar los trabajadores que necesite. Si aumenta la demanda de trabajadores, el nivel de salarios subirá, y si se necesitan menos trabajadores, el nivel del salario caerá.

El método para obtener pleno empleo es manteniendo un mercado laboral no manipulado. Esto es válido para todo tipo de trabajo: Miles de jóvenes salen cada día de las zonas rurales y llegan a las ciudades con la finalidad de ganar más dinero. Vienen a la ciudad con la idea de ganar S/ 200 semanal. Así, si un joven no puede conseguir un trabajo por S/ 200 semanal, debe tratar de conseguirlo por 150 soles semanal, o aún menos ${ }^{3}$. Pero si dijera '200 soles a la semana o nada' probablemente permanezca desempleado ${ }^{4}$.

Se puede mejorar la condición de los trabajadores y de toda la población manteniendo un mercado laboral no manipulado; y así

3 ¿Qué hace un empresario que desea vender cierta mercadería por 5 soles la unidad? Cuando no puede venderla a ese precio, 'la mercadería no sale' Pero la mercadería debe salir. No puede retener mercadería; porque debe comprar nueva mercadería ya que los costos y la moda están cambiando. Entonces vende a un precio más bajo. No tiene otra alternativa si quiere permanecer en el negocio. Puede sufrir pérdidas pero esta pérdida se debe al hecho que su previsión del mercado para su producto, fue errónea.

4 A muchos no les preocupa estar desempleados porque el gobierno les apoya mediante programas de empleo temporal y programas financiados por impuestos especiales cobrados a los empresarios, que a veces son casi tan altos como los salarios que el hombre recibiría si estuviera empleado. 
alcanzar el pleno empleo. Será tal mercado que determine el nivel de salarios.

La inflación es una política deliberada de los gobiernos que recurren a ella porque consideran que es un mal menor que el desempleo. Pero, en (el no muy largo plazo) la inflación no cura el desempleo

La inflación es una política, y una política puede cambiarse. Si uno considera que la inflación es un mal; uno tiene que parar de provocarla. Se debe equilibrar el presupuesto del gobierno. La opinión pública debe apoyar a esta acción. Si se obtiene el apoyo de la opinión pública, es posible -para el gobierno- abandonar las políticas inflacionarias. Pero debemos arreglar nuestros asuntos monetarios -en el corto plazo- de la mejor manera posible. $Y$ una de las medidas necesarias para ese objetivo es abandonar las políticas inflacionarias.

\section{INVERSIONES EXTRANJERAS}

La gente considera insatisfactoria las grandes diferencias en el nivel de vida de los países. Los países que no han alcanzado el nivel de vida de los países desarrollados creen que hay algo que no está bien en su propia situación económica.

El nivel de vida en los países en desarrollo es más bajo porque la utilidad proveniente del mismo tipo de trabajo; es más bajo en esos países que en los países desarrollados.

Causa de esta diferencia: las condiciones que prevalecen en el país desarrollado hacen posible que el trabajador de ese país gane salarios más altos. Si un peruano se va a EEUU, rápidamente estará ganando un salario de un nivel habitual en EEUU. Y si el mismo peruano vuelve a Perú, descubrirá que su visita a EEUU no le ha dado cualidades que le permitan ganar en Perú, salarios más altos que sus paisanos.
En Perú, el equipamiento de las fábricas y los métodos tecnológicos empleados son inferiores a los que se encuentran en EEUU. Los empresarios peruanos saben que las fábricas en EEUU están mejor equipadas. Ellos saben todo lo que es necesario sobre tecnología, y si no lo saben, tiene la oportunidad de aprender lo que necesitan conocer a través de libros y revistas técnicas que divulgan estos conocimientos.

La diferencia es la cantidad de bienes de capital disponibles. La cantidad de capital invertido por habitante es mayor en EEUU que en Perú.

Un empresario no puede pagar a un trabajador por encima del valor agregado (por el trabajo adicional de ese trabajador) al valor del producto. No puede pagarle más que lo que los clientes están dispuestos a pagar por ese trabajo adicional de ese trabajador. Si le paga más, no lo recuperará de sus clientes. Incurrirá en pérdidas y, un empresario que sufre pérdidas debe cambiar sus métodos de hacer negocio o se irá a la quiebra.

Así, los salarios son determinados por la productividad marginal del trabajo. La escala de salarios es determinada por el monto por el cual la labor del trabajador incrementa el valor del producto. Si una persona trabaja con herramientas más eficientes; puede rendir en una hora mucho más que una persona que trabaja una hora con herramientas menos eficiente. 100 obreros trabajando en una fábrica china de zapatos, equipada con las más modernas herramientas y máquinas, producen mucho más, en el mismo período de tiempo, que 100 obreros de calzado en Perú, que deben trabajar de una forma menos sofisticada, con herramientas anticuadas.

Los empresarios de los países en desarrollo saben que mejores herramientas permitirán que sus empresas sean más rentables. Les gustaría construir más y mejores 


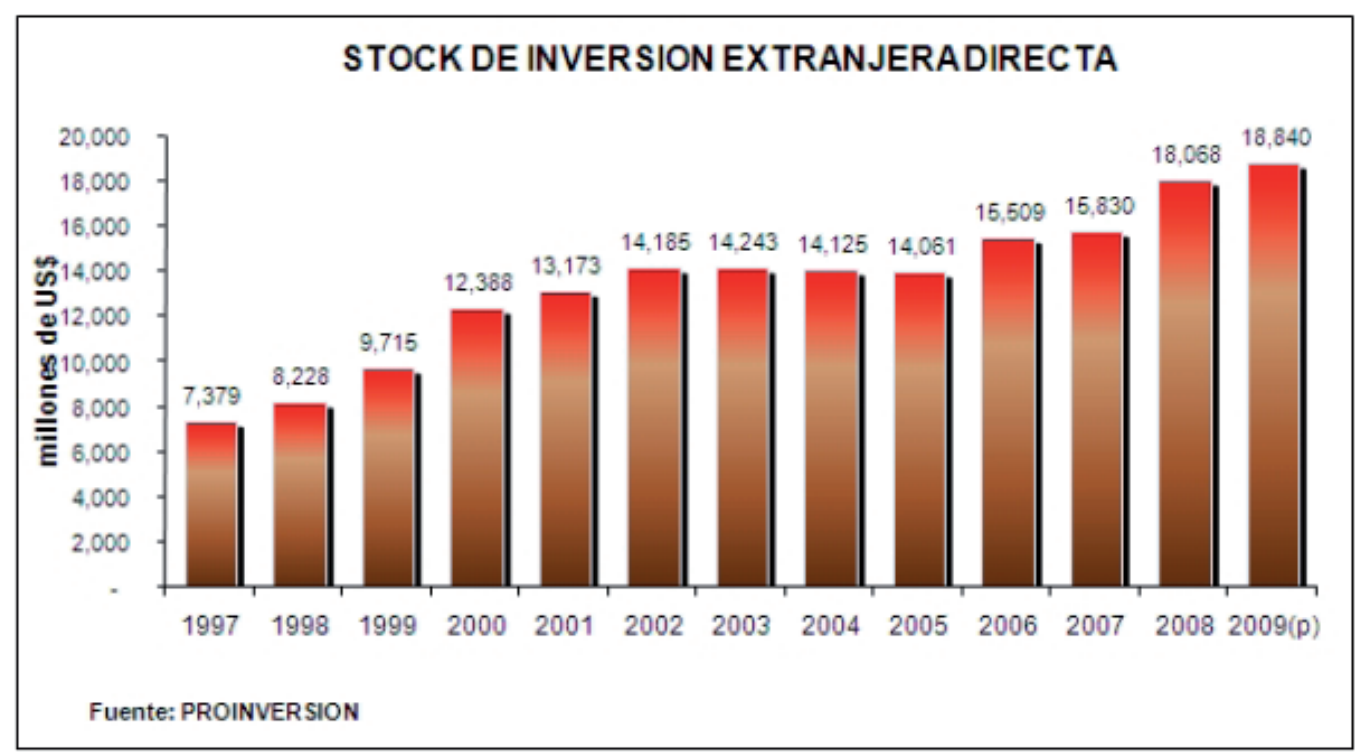

fábricas. Lo que le impide hacerlo es la escasez de capital.

La diferencia entre países en desarrollo y países desarrollados es una función de tiempo. Los países desarrollados comenzaron a ahorrar antes que los países en desarrollo. Comenzaron a acumular capital e invertirlo antes en negocios. Como comenzaron antes, existe un más alto nivel de vida en los países desarrollados que los países en desarrollo. Los países en desarrollo, comenzaron a estudiar las condiciones de los países desarrollados y descubrieron la causa de la riqueza de los países desarrollados. Así comenzaron a imitar los métodos de negocio de los países desarrollados. Como los países en desarrollo comenzaron más tarde y los países desarrollados no se detuvieron en su inversión de capitales, quedaba todavía una diferencia entre las condiciones de los países desarrollados y las condiciones de los países en desarrollo.

El desarrollo de la inversión extranjera hizo desaparecer la ventaja de lo países desarrollados. El capital podía ser invertido fuera del país desarrollado. Los capitalistas tratarían de invertir en el extranjero. Las inversiones de capital en el exterior comenza- ron a jugar un rol importante en los asuntos mundiales.

Sin inversión de capital extranjero, habría sido necesario para los países en desarrollo, comenzar con los métodos y tecnología con que habían comenzado los países desarrollados, y lentamente, paso a paso (siempre muy por debajo del nivel tecnológico de la economía de países desarrollados) tratar de imitar lo que los países desarrollados ya habían hecho.

Les habría tomado -a estos países en desarrollo- muchas décadas para alcanzar el nivel de desarrollo tecnológico que los países desarrollados habría alcanzado cien años antes que ellos. Pero el gran acontecimiento que ayudó a los países en desarrollo fue la inversión extranjera.

Inversión extranjera significa que los capitalistas invirtieron capital en otras partes del mundo. Invirtieron en los países que tenían escasez de capital y estaban retrasados en su desarrollo.

Las telecomunicaciones de los países en desarrollo, fueron construidos con la ayuda del capital de los países desarrollados. Las empresas eléctricas de los países en desarrollo fueron de los países desarrollados. 
El capital de los países desarrollados desarrolló las empresas eléctricas las telecomunicaciones y otras ramas de la industria de los países en desarrollo. A medida que Perú importa capitales, su balanza comercial se vuelve 'deficitaria'. Esto significa que tiene un exceso de importaciones sobre las exportaciones. El motivo de la superavitaria balanza comercial de los países desarrollados, era que las fábricas de estos países enviaban mucho equipamiento a Perú y este equipamiento era pagado en dinero o con las acciones de las empresas peruanas.

Cuando Perú, con la ayuda del capital extranjero - $y$ de sus propias políticas económicas- desarrolló su propio sistema económico, los empresarios peruanos comenzaron a recomprar las acciones que antes se habían vendido a los extranjeros. Entonces Perú tenía un excedente de exportaciones sobre importaciones. La diferencia fue cancelada con la importación y la repatriación de las acciones de las empresas peruanas.

Este período se prolongó hasta el 2003. Lo que ocurrió después es la historia de los subsidios otorgados a los sectores sociales; los préstamos, las inversiones Estatales en los gobiernos regionales. La inversión de capital extranjero tuvo un rol importante en el desarrollo de las industrias.

La modernización de aeropuertos, puertos marítimos, empresas y minas, lo hizo la inversión extranjera.

La inversión extranjera se realiza con la expectativa de que no será expropiada. Nadie invertiría nada si supiera con anticipación que alguien expropiaría su inversión. Se realizaron inversiones extranjeras en el período 19932010 gracias a la Constitución de 1993. Al inicio, algunos sectores sociales tenían cierta hostilidad al capital extranjero, pero luego se dieron cuenta de que se obtenían una enorme ventaja de esas inversiones extranjeras.
En algunos casos, estas inversiones extranjeras son hechas indirectamente mediante préstamos al gobierno. El gobierno usaba el dinero para las inversiones. Así fue el período 2004-2010. Por razones políticas, los Norteamericanos invirtieron en Perú, 2 mil millones de dólares, prestándolo al Gobierno peruano. Todas las grandes infraestructuras y proyectos del Gobierno peruano fueron realizadas con el capital extranjero prestado al Gobierno peruano. Los Norteamericanos no creen que el Gobierno peruano del 20112016 declare no pagar la deuda incurridas por sus predecesores.

En Octubre de 1968 comenzó un período de guerra abierta contra la inversión extranjera. Como no había remedio para prevenir que un gobierno expropie el capital invertido, no existía protección legal para las inversiones extranjeras. Los capitalistas no previeron esto. Si los capitalistas de los países exportadores de capital se hubieran dado cuenta de ello, todas las inversiones extranjeras habrían terminado hace 42 años. Pero esos capitalistas no creían que el país fuera tan falto de ética como para incumplir una deuda o expropiar y confiscar la inversión extranjera. Desde 1990 las inversiones extranjeras ayudaron a desarrollar los modernos métodos de transporte, manufactura, minería, agricultura y comunicaciones.

La actual situación en Bolivia, Venezuela y Ecuador creada por el sistema de expropiación del capital extranjero, consiste en la expropiación directa y expropiación indirecta a través de controles de cambio o de impuestos discriminatorios. Este es un problema de esos países en desarrollo.

Bajo el sistema económico del período 1950-1967, el capital extranjero invirtió en Perú. Y los extranjeros exportaron a Perú algo más: exportaron a Perú modernos métodos para combatir las enfermedades infec- 
ciosas. El resultado fue un notorio aumento de la población y un aumento de los problemas demográficos. Enfrentada a una situación que empeoraba, Perú se volvió hacia la expropiación como un medio de solucionar esos problemas. Pero no siempre fue una expropiación directa; el Gobierno hostigó a los capitalistas extranjeros, obstaculizando sus negocios de tal manera que estos inversionistas extranjeros se vieron obligados a malvender sus empresas. Además, Perú pudo acumular capital por otro método: la acumulación interna de capital. Sin embargo, Perú era tan hostil a: la acumulación interna de capital como al capital extranjero. Velasco decía que deseaba industrializar el país, pero lo que tenía en mente era tener empresas estatales. Velasco presentó un Plan con la intención de hacer más atractiva la inversión extranjera en Perú.

El problema es la acumulación interna de capital. Existe doble impuesto a las empresas. Primero, las utilidades de las empresas están sujetas a altos impuestos. Segundo, los dividendos que esas empresas pagan a sus accionistas están nuevamente sujetos a impuestos. $Y$ esto se hace de forma progresiva.

El impuesto progresivo a las utilidades y dividendos significa que esa parte de las utilidades (que la gente podría haber ahorrado y vuelto a invertir) se elimina con los impuestos. El impuesto a las sobre ganancias significa que por cada nuevo sol ganado; la empresa retenía solamente 40 céntimos. Cuando esos 40 céntimos eran pagados como dividendos a los accionistas; aquellos que tenían una gran cantidad de acciones tenían que pagar otros 40 céntimos. Del nuevo sol de utilidad solamente podía guardarse 40 céntimos y los otros 60 céntimos iban al Gobierno. De estos 60 céntimos, una gran parte podría haberse ahorrado o reinvertido. En cambio, el Gobierno lo usaba para gastos corrientes.
En muchos países en desarrollo el problema es muy crítico. No hay ahorro interno, y la inversión de capital desde el exterior se reduce considerablemente por el hecho de que estos países son abiertamente hostiles a la inversión extranjera. ¿Cómo pueden hablar de industrialización, de la necesidad de desarrollar nuevas plantas, de mejorar condiciones, de elevar el nivel de vida, de tener mejores salarios, mejores medios de transporte; si hacen cosas que tienen el efecto contrario? Lo que sus políticas logran es impedir la acumulación de capital interno, o reducir su tasa de crecimiento, y poner obstáculos para la llegada del capital extranjero.

El resultado final es muy malo. Tal situación ocasiona una pérdida de confianza, y hay cada vez más y más desconfianza de la inversión extranjera. Aún si esos países cambiaran inmediatamente sus políticas e hicieran todas las promesas posibles, se duda que pudieran una vez más inspirar confianza a los capitalistas extranjeros para que inviertan.

Métodos para evitar estas consecuencias: establecer un Estatuto Internacional que sacará el tema de las inversiones de las jurisdicciones nacionales. Esto lo podrá hacer las Naciones Unidas. Dándose cuenta de la enorme importancia de la inversión extranjera, comprendiendo que las inversiones extranjeras pueden producir un mejoramiento en las condiciones políticas y económicas mundiales; se podría tratar de hacer algo desde el ángulo de la legislación internacional.

Este es un problema técnico-legal, que solamente se menciona, ya que la situación no es desesperada. Si el mundo quisiera hacer posible a los países en desarrollo elevar su nivel de vida al nivel de EEUU, entonces podría hacerse. Solamente es necesario entender cómo podría hacerse.

Lo que falta para hacer prósperos a los países en desarrollo es capital y libertad para 
utilizarlo bajo la disciplina del mercado y no bajo la disciplina de los gobiernos. Estos países deben promover la acumulación de capital nacional y hacer posible que los capitales extranjeros lleguen a sus países.

Para desarrollar el ahorro interno es necesario mencionar que el ahorro interno de la gente supone la existencia de una unidad monetaria estable. Esto implica la ausencia de cualquier clase de inflación.

Se espera que una gran parte del capital utilizado por las empresas peruanas sean propiedad de los mismos trabajadores y de otra gente de modestos recursos. Millones de soles en depósitos en cajas de ahorro, bonos y pólizas de seguro sean el capital utilizado por estas empresas. Se espera que en el mercado financiero peruano, los grandes prestamistas de dinero no sean más los bancos sino las compañías aseguradoras, cuyo dinero es propiedad -no técnicamente pero sí desde el punto de vista económico- de los asegurados. Y cualquier persona en Perú está asegurada, de una u otra forma. El prerrequisito para una mayor igualdad económica en el mundo es la industrialización. $Y$ ésta es posible a través de un incremento en la inversión de capital, una mayor acumulación de capital. No se ha mencionado una medida que se considera el método para industrializar un país. Se habla del proteccionismo. Pero las tarifas y los controles de cambio son los medios para impedir la inversión de capital en un país y su industrialización. El camino para incrementar la industrialización es tener más capital. El proteccionismo desvía las inversiones de un sector de negocios a otro sector. El proteccionismo, por sí solo, no agrega nada al capital de un país. Para instalar una nueva fábrica uno necesita capital. Para mejorar una fábrica ya existente uno necesita capital, no una tarifa proteccionista.
El proteccionismo y el sindicalismo no mejoran la situación económica de un país. $\mathrm{Si}$ los salarios son bajos, si el trabajador de un país pobre mira a EEUU y lee sobre lo que pasa allí, si ve en las películas como el hogar de un Estadounidense está equipado con todo el confort moderno, puede tener envidia. Tiene toda la razón en decir "Deberíamos tener lo mismo". Pero la única manera de obtenerlo es aumentando el capital.

Los sindicatos usan la violencia contra empresarios y gente (a quienes llaman "rompehuelgas"). Sin embargo, a pesar de su poder $\mathrm{y}$ violencia, los sindicatos no pueden elevar los salarios, continuamente, para todos los asalariados. Igualmente inefectivos son los decretos gubernamentales fijando salarios mínimos. Lo que los sindicatos logran, si tienen éxito en elevar las escalas salariales, es un permanente desempleo.

Pero los sindicatos no pueden industrializar el país, no pueden elevar el nivel de vida de los trabajadores. Todas las políticas de un país, cuyo objetivo sea mejorar el nivel de vida, deben dirigirse hacia un incremento de la inversión de capital per cápita. Esta medida de inversión de capital per cápita todavía se está incrementando en Perú, a pesar de todas sus malas políticas.

La población mundial se está volviendo cada vez más grande, quizás 10 millones de personas por año. En 1950 los peruanos pensaban que 7 millones de habitantes era una tremenda sobrepoblación y que estabamos encaminados hacia hambrunas y plagas. Pero a comienzo del 2011, 30 millones de habitantes viven en Perú con un nivel de vida superior al que tuvimos en 1950. Esto fue el efecto de la industrialización. El progreso de Perú se origina en el incremento de la inversión de capital per cápita. Existe un camino para que un país logre la prosperidad. Si se incrementa el capital, se incrementa la pro- 
ductividad marginal del trabajo, y el resultado será que los salarios reales se elevarán. En un mundo sin barreras a la migración, había una tendencia mundial hacia el igualamiento de los niveles salariales.

Existe otro método para igualar los niveles salariales en todo el mundo: la migración de capital. Los capitalistas tienden a ir hacia aquellos países donde exista una gran cantidad de fuerza laboral disponible y en los que los resultados del trabajo sean razonables. $Y$ por el hecho que exportan capital a esos países dan lugar a un a tendencia hacia mayores niveles salariales.

El capital extranjero debe ser invertido; porque los salarios son muy inferiores a los salarios de los países desarrollados. Esta inversión adicional de capital da lugar a una tendencia hacia mayores salarios. Tan pronto las empresas industriales se instalan en Perú, el resultado será una tendencia hacia mayores niveles salariales, comenzando con los salarios que pagan esas empresas industriales, lo que hace necesario que otros empleadores pagaran también salarios más altos.

La gente desea y quiere tener un mejor nivel de vida. En Perú todos desean ver mejoradas las condiciones en el país. Un más alto nivel de vida trae aparejado un más alto de nivel de cultura.

La meta final es elevar el nivel de vida en todas partes. Hay desacuerdo con las medidas que deben adoptarse para llegar a esa meta. Para llegar a esa meta jhay un método! Es un método lento. Lleva tiempo y se debe trabajar. Pero no toma tanto tiempo, y finalmente se llegará a la meta. Elevar el nivel de ingreso per cápita.

Perú es un país al que la naturaleza ha dotado generosamente. Tiene recursos naturales. Perú podría obtener un alto nivel de vida; después de algunos años de aplicar buenas políticas económicas.

64/ Quipukamayoc | Vol. 18(35) 20101
Así, los programas de libertad económica están en contra del intervencionismo gubernamental, inflación, violencia sindical y tarifas proteccionistas.

\section{CONCLUSIONES}

La gente espera: que las instituciones políticas -los gobiernos representativos constitucionales- funcionen de manera beneficiosa; y que la libertad mejore las condiciones de vida de la gente.

Algunas de estas expectativas son demasiado optimistas. Estamos experimentando una mejora en las condiciones económicas, posibilitando a una mayor población; vivir con un mayor nivel de vida.

El sistema constitucional ha desilusionado a la gente. Existe conexión entre el lado económico y el lado político de este problema. El deterioro del sistema parlamentario (el gobierno llevado a cabo por los representantes del pueblo) es dependiente de la situación económica y las ideas económicas que condicionan las actividades de la gente. El deterioro de la libertad, del gobierno constitucional y de las instituciones representativas, es consecuencia del cambio en las ideas económicas y políticas económicas. Los acontecimientos políticos son consecuencia del cambio en las políticas económicas.

Las ideas que guían a estadistas y juristas parten del supuesto de que: en un país todos los ciudadanos honestos tendrían el mismo objetivo final. Este objetivo (a la cual se dedican todos los ciudadanos honestos) es el bienestar del país. Ciudadanos que están convencidos de que un país libre no debe estar interesada en conquistas y que conciben los conflictos entre partidos políticos como algo natural ya que es normal que hubiera diferencias de opinión sobre la mejor manera de conducir los asuntos de Estado. 
La gente que sostuviera ideas similares sobre un problema cooperarían entre ellos, y esta forma de cooperación se denomina partido político. La estructura de un partido puede cambiar; si la gente se da cuenta que su postura social original estaba basada en supuestos erróneos. Desde este punto de vista las discusiones en una campaña electoral y en los Plenos; es un factor político importante. Los discursos de los congresistas se consideran como intentos de convencer a los grupos adversarios: que las ideas propias del orador son correctas, más beneficiosas para el bien común; que aquellas ideas que habían escuchado antes.

Los discursos políticos son escritos con el objetivo de convencer. Existen pocas razones para creer que no se podría convencer a la mayoría; que la posición propia es correcta y que las ideas propias son sanas. Desde este punto de vista se escribieron las reglas constitucionales en los cuerpos legislativos.

Pero esto supone que el Gobierno no interferiría en las condiciones económicas del mercado. Implica que todos los ciudadanos tiene un objetivo político: el bienestar del país. Este modo de pensar social y económico ha sido reemplazado por el intervencionismo. El intervencionismo ha generado un diferente modo de pensar.

Bajo las ideas intervencionistas, es tarea del Gobierno subsidiar y dar privilegios a ciertos grupos. La idea de los gobernantes era que los legisladores tenían ideas específicas (quizás diferentes) sobre el bien común. Pero lo que vemos en la realidad de la vida política es una situación en que no existen partidos políticos en el clásico sentido del término, sino grupos de presión.

Grupo de presión es un grupo de personas que desea obtener privilegios a costa del resto del país. El privilegio puede consistir en un arancel a la importación de un producto que compita con los propios, en un subsidio, en dar leyes que impidan a otra gente competir con los miembros del grupo de presión. Otorga a los miembros del grupo de presión; un privilegio que es negado (de acuerdo con las ideas del grupo de presión) a otros grupos.

En Perú hay 4 partidos políticos Partido Nacionalista, Fuerza 2011, Perú Posible y Apra. Pero esto es un camuflaje de la situación real. La vida política está determinada por la lucha y aspiraciones de los grupos de presión. En cada uno de esos 4 partidos hay representantes de los grupos de presión. Estos representantes están más interesados en cooperar con los representantes del mismo grupo de presión en el partido adversario que con los miembros de su propio partido.

La gente que conoce los asuntos del Congreso, dice: Este Congresista, representa los intereses del grupo de la Confiep o este otro Congresista representa a los productores de coca.

Cada grupo de presión que aspira a tener privilegios; es una minoría. Y las minorías nunca tienen la oportunidad de alcanzar el éxito si no cooperan con otros grupos de presión similares. En el Pleno, tratan de armar una coalición entre los diferentes grupos de presión, para convertirse en una mayoría. Pero, después de un tiempo, esta coalición se desintegra, porque existen problemas en los que es imposible alcanzar un acuerdo con otros grupos de presión, y se forman nuevas coaliciones de grupos de presión

El sistema de grupos de presión no es un sistema que pueda aplicarse exitosamente al gobierno de un país.

En las legislaturas, se tienen representantes de la confiep, de los productores de coca, de los exportadores, del petróleo y de los sindicatos. La única cosa que no está representada en la legislatura es el país como un todo. $Y$ todos los problemas, aún los de política exte- 
rior, se miran desde el punto de vista de los intereses de los grupos de presión

Las entidades estatales están interesadas en el salario de sus burócratas. Pero no todos los peruanos están interesados en ello. Sin embargo, el país, por muchas décadas, ha gastado una considerable suma de dinero, a costa de los contribuyentes, para pagar salarios en un monto por encima del salario de mercado. En el país, sólo una pequeña parte de la población trabaja en Petroperú, el resto de la población son consumidores directo e indirecto de los productos de Petroperú. Sin embargo, el país tiene una política de gastar millones de soles para mantener los precios de la gasolina por encima del precio internacional de mercado.

Petroperú preferiría un menor precio para sus insumos. Existen muchos intereses especiales incompatibles dentro de Petroperú. Aún así, la hábil diplomacia de los congresistas posibilita a Petroperú obtener privilegios a costa de la mayoría.

Una situación concierne a la gasolina. 1 de cada 9000 peruanos desea un precio más alto para la gasolina. 8999 de cada 9000 peruanos desea un precio más bajo para la gasolina. Sin embargo, la política peruana está comprometida (mediante tarifas y otras medidas especiales) a mantener un alto precio de la gasolina. Esta política es perjudicial para esos 8999 que son consumidores directo e indirecto de gasolina, y también causa un serio problema en la política exterior peruana. El objetivo de la política exterior es la cooperación con los otros países, algunas de las cuales están interesados en vender gasolina al Perú. Les gustaría vender un mayor volumen. Esto ilustra cómo los intereses de los grupos de presión pueden establecer la política exterior de un país.

La gente se queja de las deficiencias de la democracia, pero la democracia que ellos critican es aquella democracia bajo la cual el intervencionismo es la política que gobierna el país.

Los congresistas hablan sobre mantener los impuestos altos y crear nuevos impuestos.

Estos cambios políticos, originados por el intervencionismo, han debilitado el poder de los gobiernos y de sus representantes populares, para resistir las aspiraciones de dictadores y operaciones de tiranos. Los congresistas, cuya preocupación es satisfacer a ciertos votantes que desean mayor precio para la gasolina y menor precio para los insumos de la gasolina (subsidiado por el gobierno) representan a pequeños grupos de votantes, no a todos los votantes.

Los votantes que se ven favorecidos por esos privilegios no se dan cuenta que también hay oponentes, que desean algo opuesto, e impiden a sus representantes obtener un éxito completo.

Además, este sistema conduce a un constante aumento del gasto público; y hace más difícil cobrar impuestos. Estos representantes de los grupos de presión aspiran a muchos privilegios especiales para su grupo de presión, pero no están dispuestos a imponer a sus votantes una pesada carga impositiva.

El que un congresista solo represente los intereses del departamento por el que fue elegido, fue una de las consecuencias del intervencionismo. La idea era que cada congresista represente a todo el país aunque fuera elegido por un departamento (solamente porque allí era conocido y la gente tenía confianza en él).

Pero no era intención del congresista procurar algo en especial para sus votantes, que pidieran una nueva escuela o un nuevo hospital, causando así un considerable incremento de los gastos públicos en su departamento. Las políticas de los grupos 
de presión explican por qué es casi imposible para los gobiernos detener la inflación. Tan pronto como los nuevos funcionarios del gobierno tratan de restringir los gastos públicos o limitar las inversiones estatales; aquellos que respaldan intereses especiales, que obtienen ventajas de rubros específicos del presupuesto, se adelantan y declaran que este proyecto no debe eliminarse, o que este otro proyecto debe realizarse.

Un gobierno autoritario no es una solución para los problemas de la economía. Un gobierno autoritario puede comenzar haciendo promesas de cualquier tipo pero, siendo gobierno autoritario, no cumplirá sus promesas. En cambio, inmediatamente censurará la libertad de prensa, así la prensa no podrá -algunos meses más tarde- remarcar que lo que dijo al comienzo de su gobierno autoritario era diferente de lo que hizo después.

Los peligros que amenazan al país es el intervencionismo y la inflación. El intervencionismo consiste en imponer controles de precios.

Las ideas intervencionistas e inflacionistas han sido formuladas por intelectuales; las cuales pueden derrotarse con otras ideas.
Debemos refutar las ideas que promueven la violencia; y oponernos a la confiscación de la propiedad privada, el control de precios, la inflación y todos los males que nos traen problemas.

\section{REFERENCIAS BIBLIOGRÁFICAS}

1. Barro Robert J. Macroeconomía. Alianza editorial. Segunda edición 1990.

2. Friedman Milton. Moneda y desarrollo. Editorial Ateneo. 1985

3. Friedman Milton. Teoría de Precios. Segunda Edición 1976.

4. Kemmerer, Edwin Walter. El ABC de la inflación. BCRP.

5. Mundell Robert A. El hombre y la economía. 1978

6. Ropcke, Wilhelm. Economía Política. Alianza Editorial. 1967

7. Rothbard Murray N. Moneda libre y controlada. Centro de estudios sobre la libertad. 1980

8. Von Hayek, Friedrich. Precios y Producción. Mc Graw Hill. 1960

9. Von Mises Ludwig. Reconstrucción Monetaria. Centro de estudios sobre la libertad. 1975

10. Von Mises Ludwig. Acción Humana. Fundación Ignacio Villalonga. 1981 